\title{
Sustainable Development through a Rights-based Approach to Conserve Protected Areas in China
}

— Miao He; An Cliquet

Ghent University, Faculty of Law

Department of Public International Law

“The IUCN AEL", Baltimore July 1-5, 2012 


\title{
Overview
}

\author{
Background Information
}

The Existing Legal and Policy Instruments in China

Why a Rights-based Approach(RBA) is a Better Method

How to Adopt a RBA to Conserve Protected Areas in China

Conclusion 


\section{$\widehat{\text { IIIII }}_{\text {NIVERSTEIT }}$ Q Q GENT \\ FACULTEIT RECHTSGELEERDHEID}

\section{Background Information}

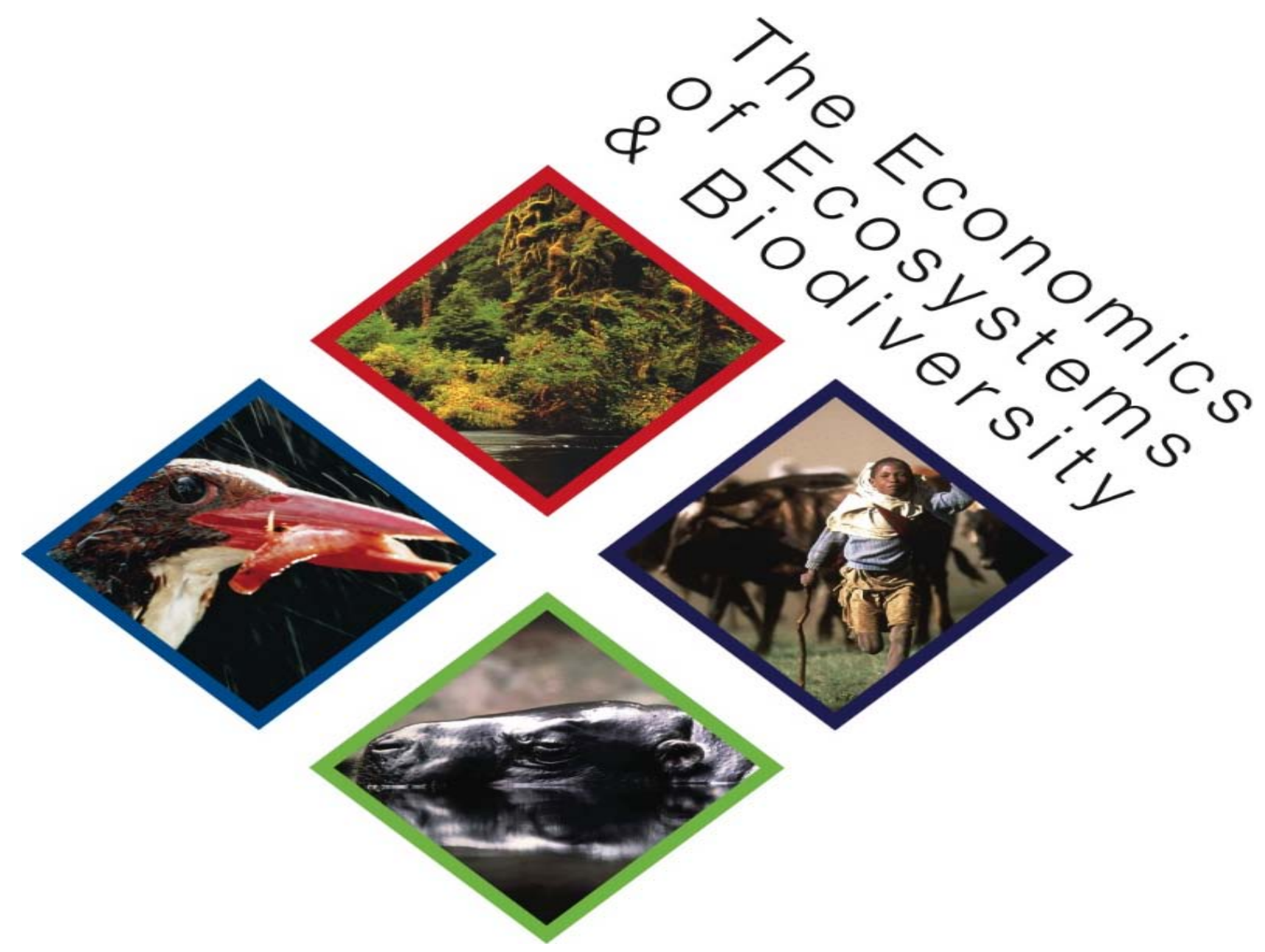




\section{IIIIII UNIVERSITEIT \\ GENT}

FACULTEIT RECHTSGELEERDHEID

\section{Background Information}

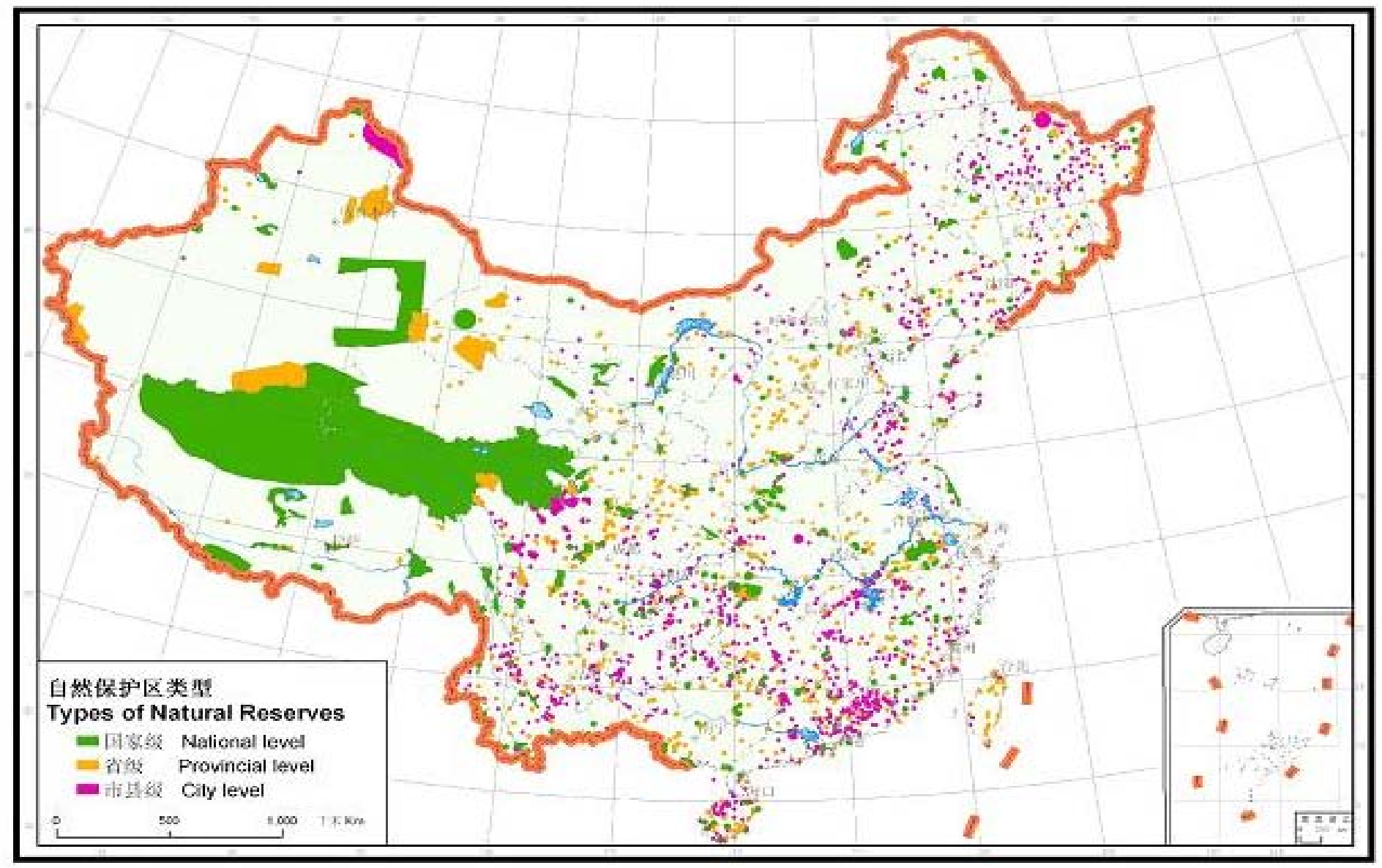

Miao He, An Cliquet Ghent University - Belgium 


\section{The Examples of Conflicts in China}

※ Yu Long Xue Shan protected area

※ Binzhou Marine Nature Reserve

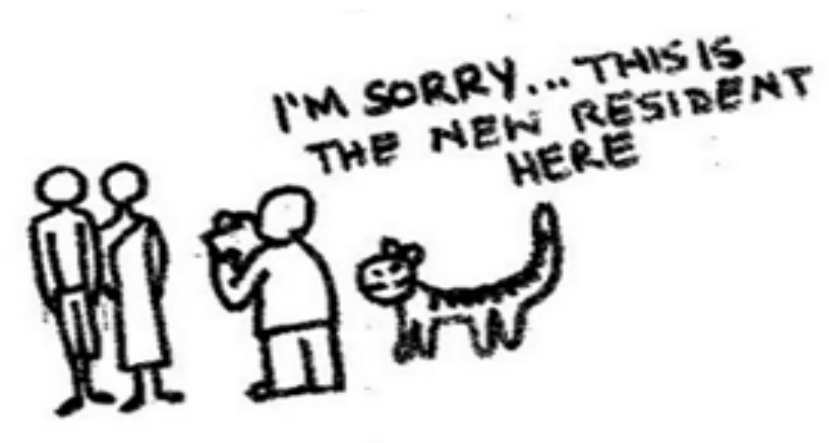




\section{$\widehat{\text { UNIIIIII }}_{\substack{\text { GERST } \\ \text { GENT }}}$}

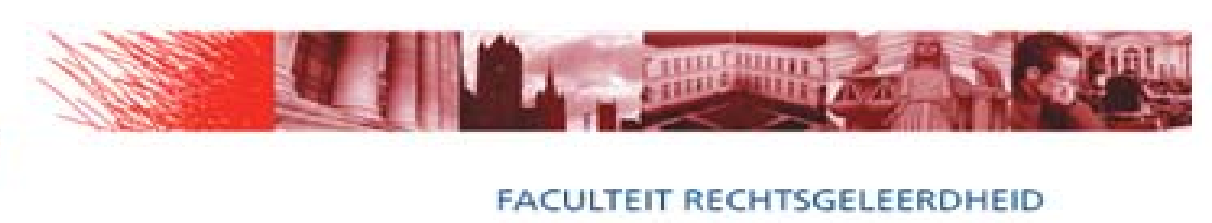

The question arises:

What channels of representation could guarantee, or at least help, local people to influence the decision-making? 


\section{$\widehat{\underline{\text { IIIIII }}}$ UNIVERSITEIT GENT}

\section{The Existing Legal System for Protected Areas in China}

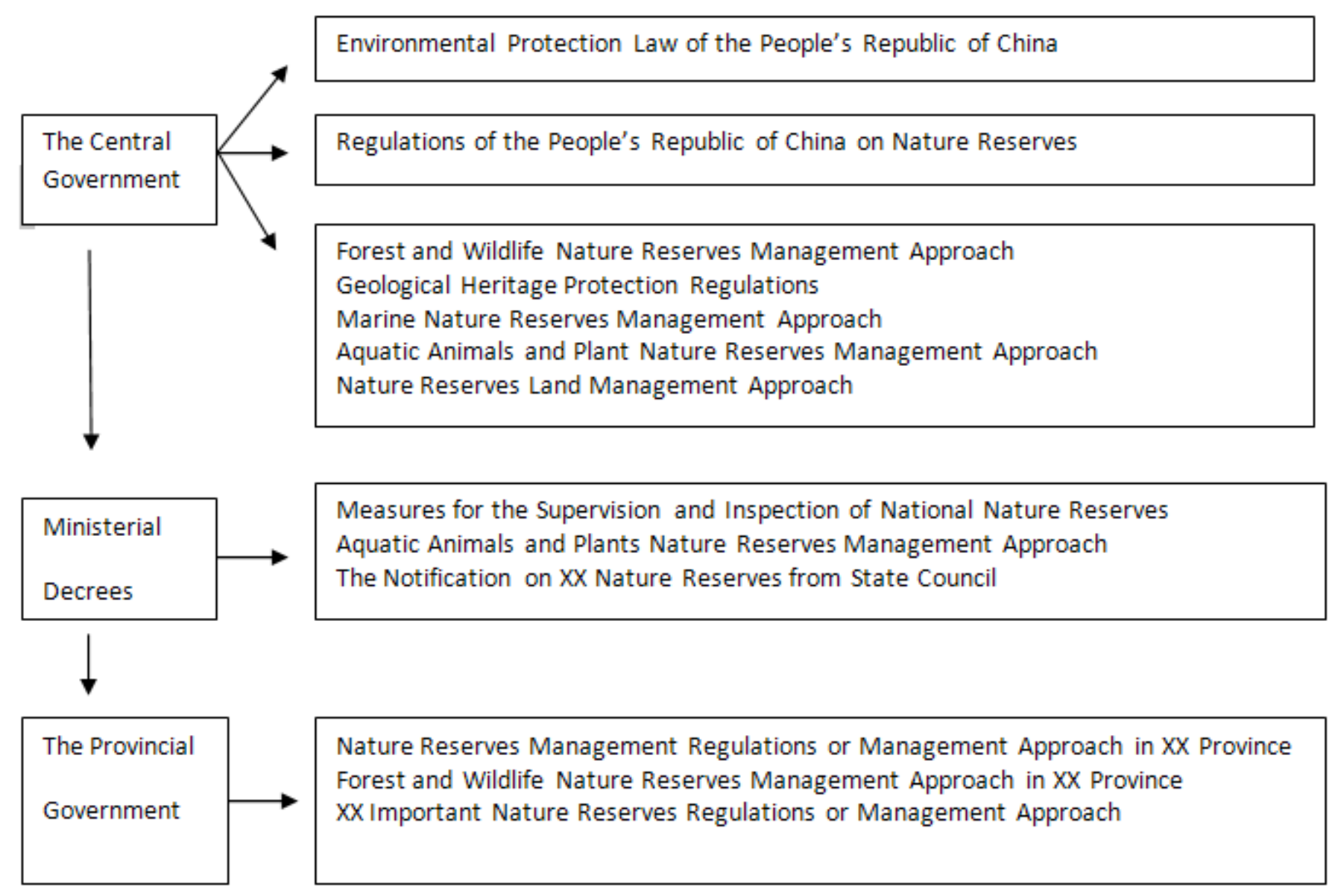

Miao He, An Cliquet Ghent University - Belgium 


\section{IIIII UNIVERSITEIT GENT}

\section{The Existing Legal and Policy Instruments Referring to the Right to Information}

-The Regulation of the People's Republic of China on the Disclosure of Government Information (2007)

-The Environmental Information Disclosure (Trail) (2007)

-The Nature Reserve Land Management Approach(1995) ---Article 13

-The National Human Rights Action Plan (2012-2050)

The Right to Information? 


\section{Some Limitations for Public Participation in China}

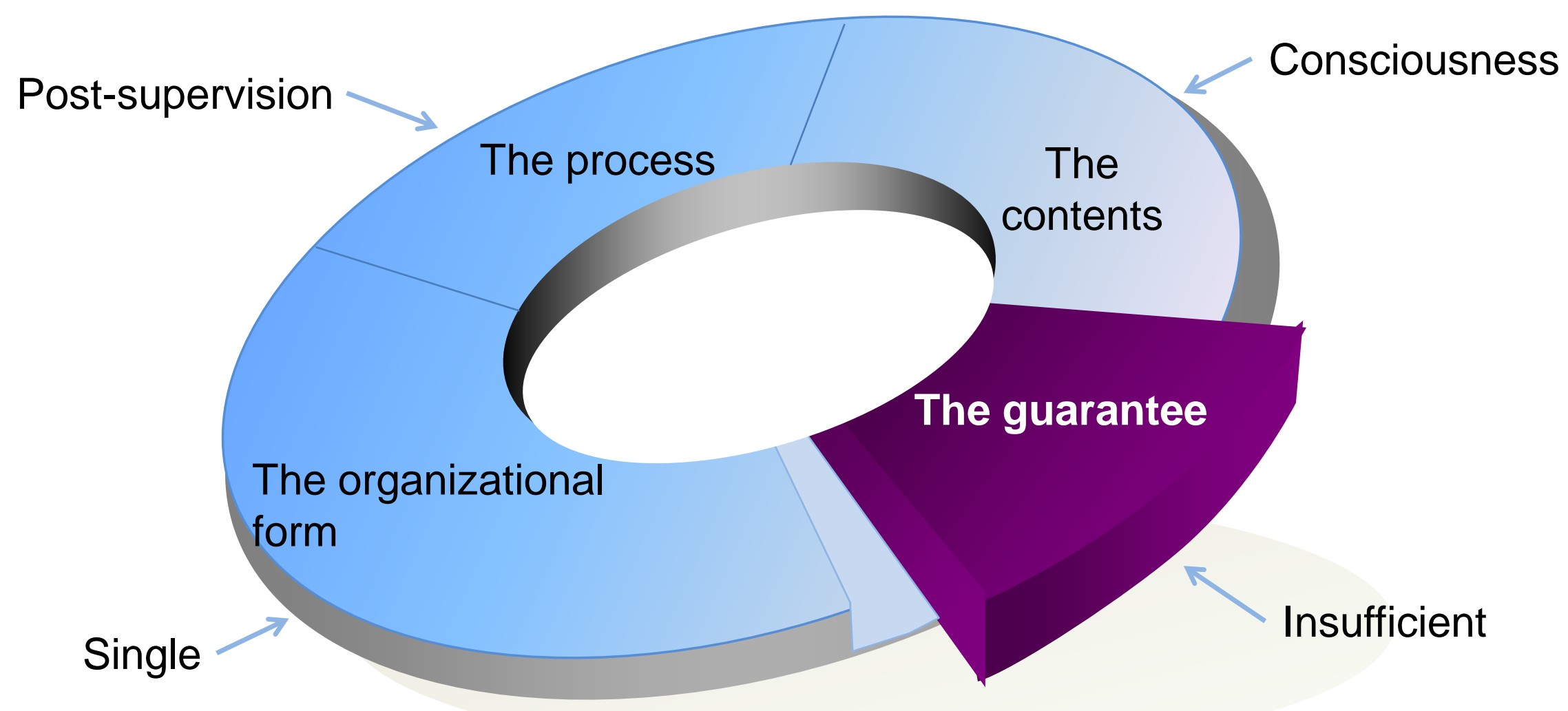




\section{The Existing Legal and Policy Instruments Referring to the Right to Participation}

-Constitution of the People's Republic of China (2004)

--- Article 2

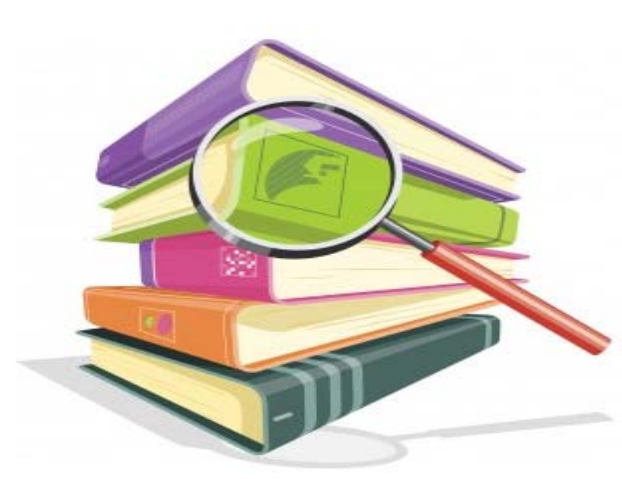

-The Regulation of the People’s Republic of China on Nature Reserves (1994) -

-- Article 7

•Chinese Agenda 21 (1994)

-Water Pollution Prevention and Control Law of the People's Republic of China (2008) 


\section{$\underline{\underline{ }}$ UNIVERSITEIT GENT}

\section{Some Improvements in the Existing Legal instruments for Public Participation}

-Special Marine Protected Areas Management Approach (2010) --- Article 13,17

-China Biodiversity Conservation Strategy and Action Plan (2011-2030) --- Action 29

-The National Human Rights Action Plan (2012-2050)

-Notification on Further Strengthening the Hydropower Construction for Environmental Protection (2012)

-The "Enshi Tujia and Miao autonomous prefecture of Hubei

Xingdoushan National Nature Reserve Management Regulation”

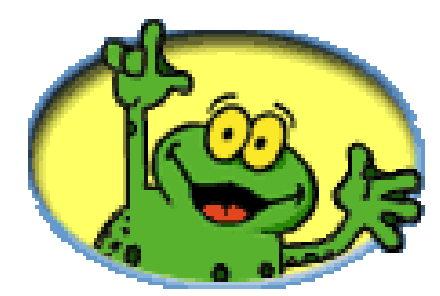



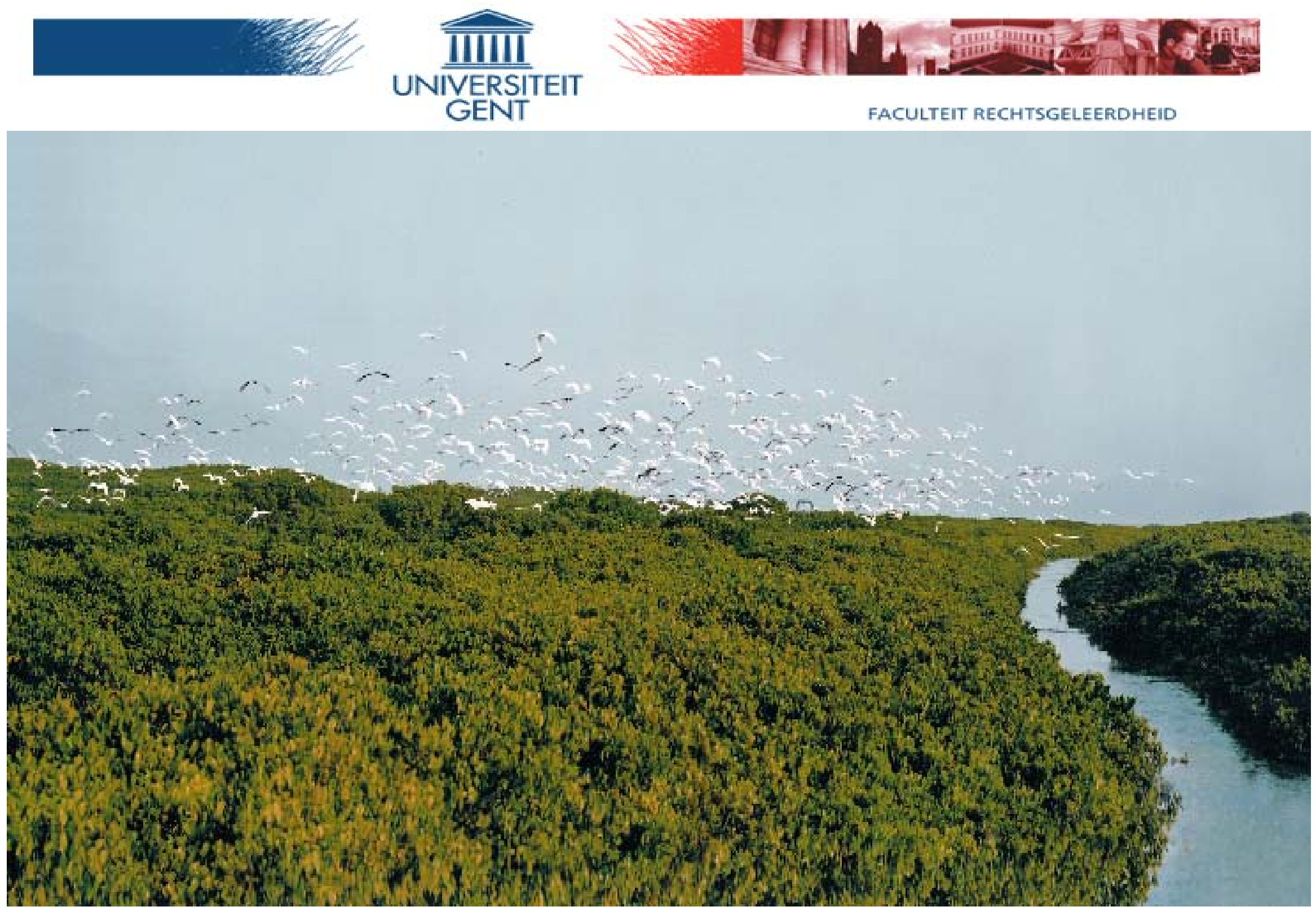

Miao He, An Cliquet Ghent University - Belgium 


\section{The General Theory of a Rights-based Approach to Conservation}

What is Rights-based Approach(RBA) to conservation?

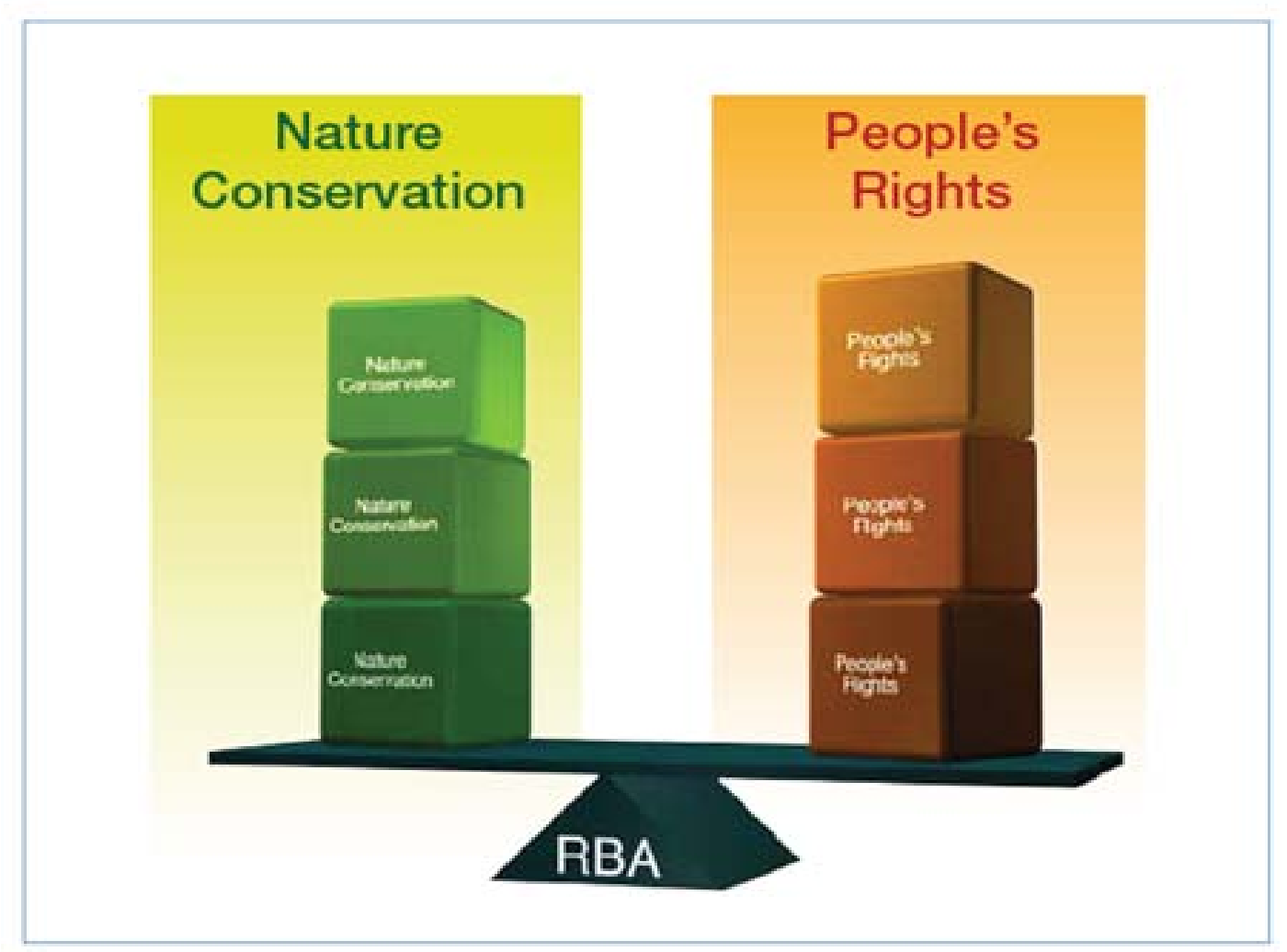

Source: Greiber T. et al. 2009 


\section{IIIIII

\section{The General Theory of a Rights-based Approach to Conservation}

Some important added-values of a rights-based approach to conservation

* Clarifying rights and duties

* Responding to increasing demands from NGOs

* Focusing on the most vulnerable

* Forming the earliest basis for international cooperation

- It is a holistic approach to achieve a long term goal

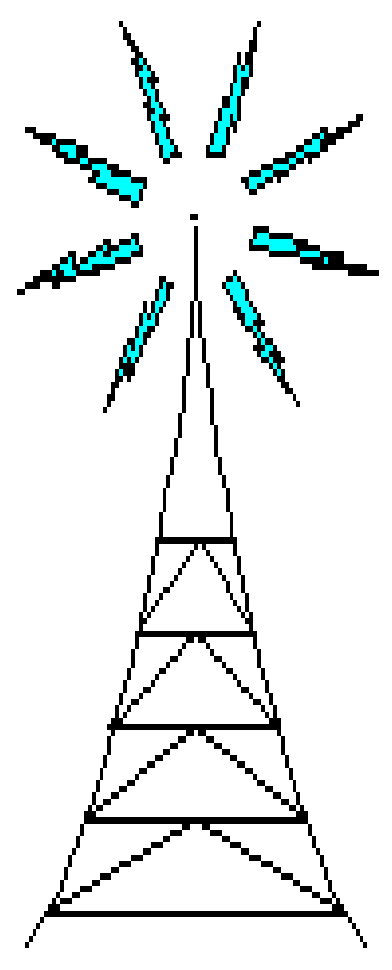




\section{$\widehat{\widehat{\text { IIIIIII }}}$ UNIVERSITEIT GENT}

\section{The General Theory of a Rights-based Approach to Conservation}

A rights-based approach is a better method but not a panacea

Challenges:

Challenges from outside

- Challenge from governments' efforts

- Challenge from global or regional human rights texts

Challenges inherent to the RBA itself

- Competition between rights

- RBA requires substantial resources of time, expertise, information, and funding to build capacity 

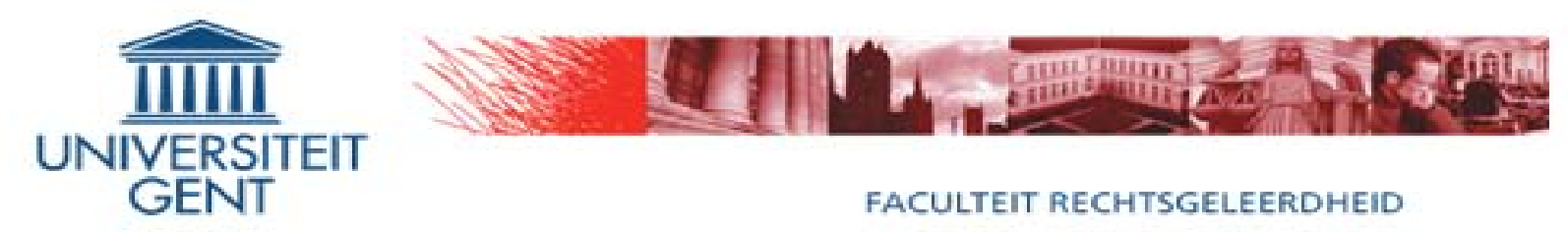

\section{How to Implement RBA to conservation in China}

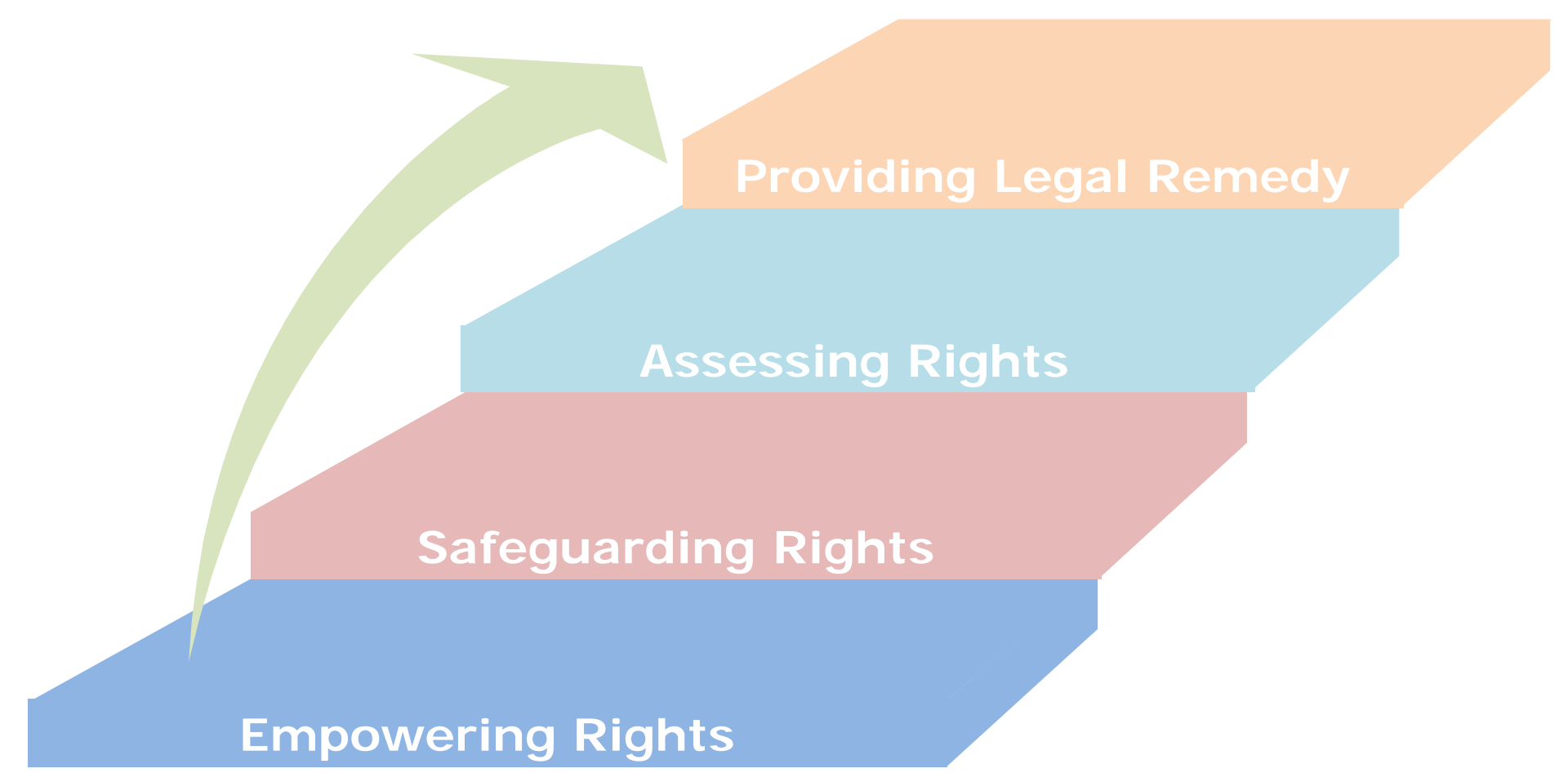




\section{$\widehat{\text { UNIIIIIII }}_{\text {GERITEIT }}$ \\ GENT}

\section{How to Implement RBA to conservation in China}

\section{* Step 1: Empowering Rights in Legislation on Protected Areas}

1) analyzing the related parties

2) dividing the power or interests for the different related parties

* Step 2:Safeguarding rights in the enforcement of legislation on protected areas

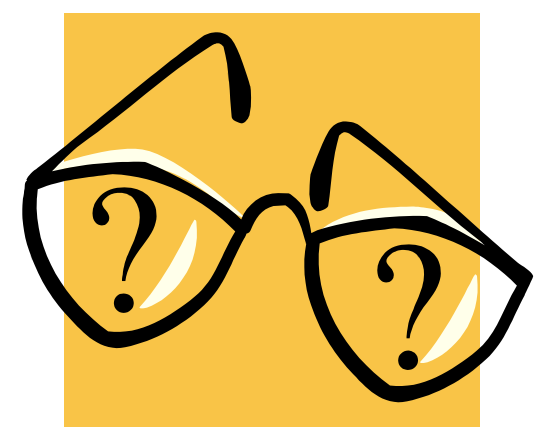

1) providing information to the related parties

2) ensuring participation

3) stimulating the enthusiasm of the related parties 


\section{How to Implement RBA to conservation in China}

* Step 3 : Assessing rights when evaluating the enforcement

* Step 4 : Providing legal remedy
1) Compensation
2) Prosecution where violation amounts to a crime when it is necessary
3) NGO's role 


\section{Conclusions}

$\star$ China has made some progress in solving the conflicts, but some problems still exist.

$\star$ A RBA can contribute to meet the need of the Chinese contemporary situation

$\star$ How to specifically implement a RBA in China needs further research

$\star$ To achieve sustainable development between protected areas and human rights need the efforts from various parties

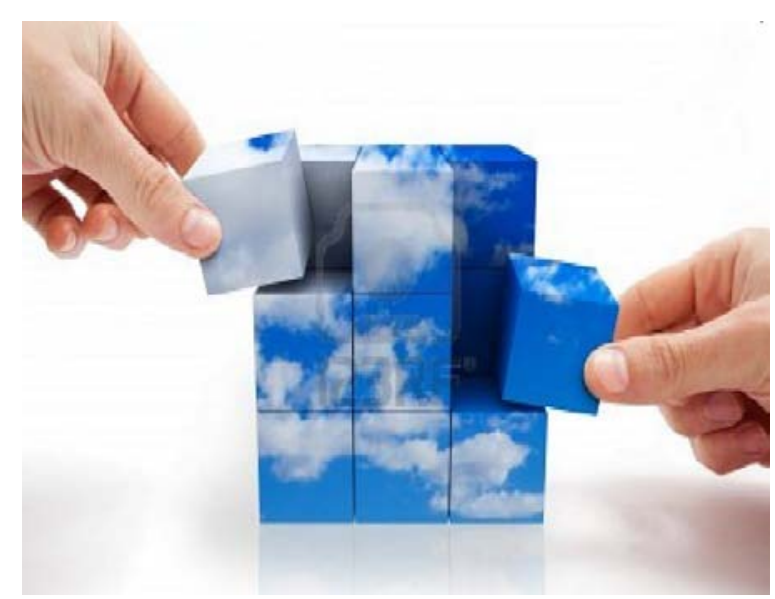




\section{IIIII UNIVERSITEIT GENT

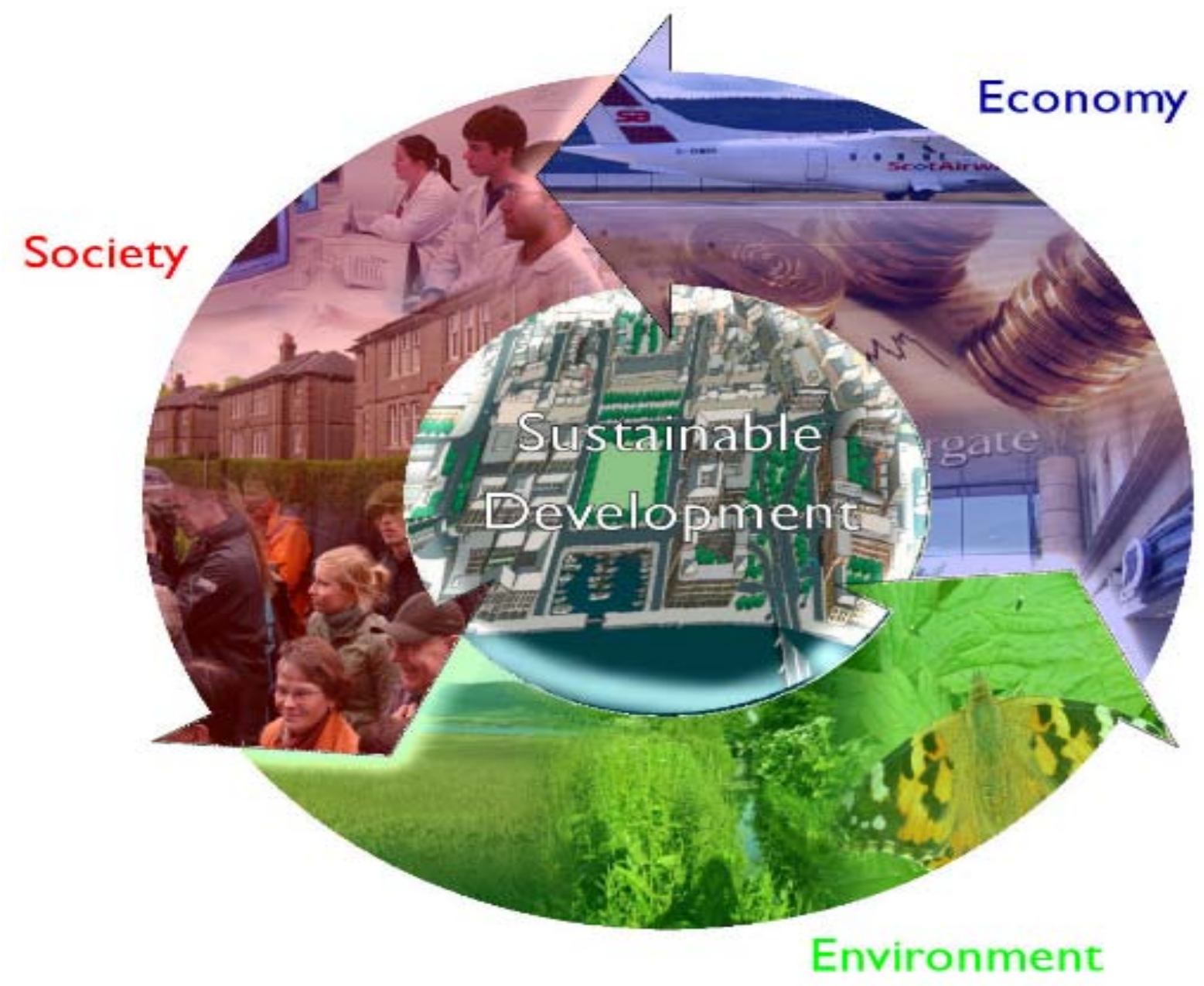




\section{IIIII UNIVERSITEIT GENT}

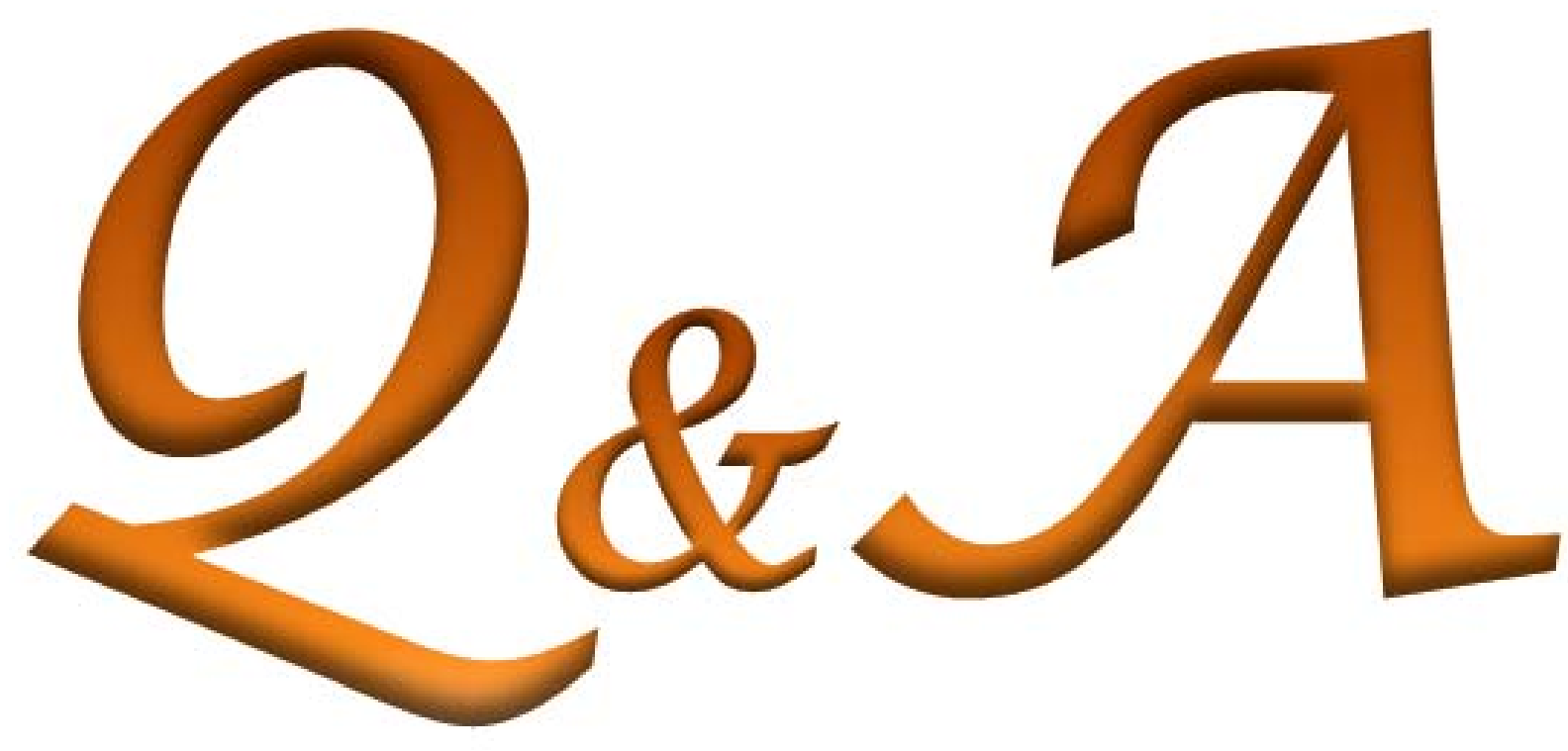

Welcome any suggestions or comments to Email: miao.he@ugent.be 